\title{
Analysis of AVO and Seismic Inversion for Reservoir Characterization (Case Study: EP Field, South Sumatera Basin)
}

\author{
H Budiman ${ }^{1 *}$, M Y N Khakim ${ }^{1}$, A K Affandi ${ }^{1}$ \\ ${ }^{1}$ Departement of Physics, Faculty of Mathematics and Natural Sciences, University of Sriwijaya, Palembang, \\ South Sumatera, Indonesia \\ *Email: budimanhendra6801@gmail.com
}

\begin{tabular}{ll}
\hline Article Information & Abstract \\
Received: & $\begin{array}{l}\text { A research about reservoir characterization with analysis of AVO (Amplitude } \\
\text { Variation with Offset) and seismic inversion, to extract the petrophysics } \\
\text { properties on the EP field South Sumatra Basin. This research was } \\
\text { conducted to identify rock lithology and its spread, to see the sensitive } \\
\text { parameters of physical properties of rocks. This research uses the } 3 D \text { seismic } \\
\text { data PSTM (Pre Stack Time Migration) as input control with data from the }\end{array}$ \\
$\begin{array}{l}\text { Received in revised form: } \\
2 \text { May } 2020\end{array}$ & $\begin{array}{l}\text { resistivity log. From the results of data analysis on the well log chart EP- } \\
\text { O36, reservoir target zones are at a depth of } 714 \text { to } 722 \mathrm{~m} \text { (TVD) or time } \\
\text { domain } 768 \text { to } 780 \text { ms. The results of the analysis AVO is able to detect the } \\
\text { Accepted: }\end{array} \quad \begin{array}{l}\text { presence of reservoir gas sand, based on the classification of Rutherford and } \\
\text { Williams (1989) the gas sand layer into AVO class III that indicates low } \\
\text { impedance contrast sands. To analyze the results of well log data in the cross } \\
\text { plot EP-036 indicates lithology is a hydrocarbon. It is also reinforced with }\end{array}$ \\
Volume 2, Issue 1, June 2020 \\
pp. 5-9
\end{tabular}

Keywords: Inversion, AVO, LMR, Reservoir Characterization.

\section{INTRODUCTION}

$I_{\mathrm{r}}^{\mathrm{n}}$ $\mathrm{n}$ the hydrocarbon exploration activities, seismic reflection is one of the most popular geophysical methods used [1]. The efforts to determine the physical properties of rocks have been in relation to the identification of rock lithology and fluid content of pore rocks or in the reservoir characterization since the 90s until now. It began from a petrophysics approach of well logging, that is a technique to get data subsurface using an instrument into the wellbore, to identify qualitative and quantitative presence of hydrocarbons [2].

One of the newly and more accurate method of data seismic interpretation to identify the rocks lithology and fluid content is AVO (Amplitude Variation with Offset). This method has been used in identification of the hydrocarbon especially gases $[3,4]$.AVO response to sandstone is more effective because the change in $\mathrm{Vp} / \mathrm{Vs}$ ratio to fluid content is relatively more sensitive than other types of rock lithologies such as carbonate rock. Seismic inversion is a subsurface geological modeling techniques using seismic data as the input and well data as the control $[5,6]$.

The research location is EP field, which is sub of South Sumatera Basin, that has substantial prospect for developing hydrocarbon exploration. However, in its implementation, this method is rarely applied in analysis and development [7]. Therefore, in this research focus on AVO analysis and seismic inversion for reservoir characterization from EP field South Sumatra Basin. The purpose of this study are to identify and determine the hydrocarbon prospect zones based on well $\log$ data, to find the most sensitive parameter in distinguishing rock lithology and fluid content and to map the distribution of the reservoir in Gumai formation based on the AVO analysis and seismic inversion. 


\section{MATERIALS AND METHODS}

This research only used one well log data, it is EP-036 well. The well $\log$ data contains of sonic, density, gamma ray, neutron and resistivity. For the seismic data, it used 3-D seismic PSTM (Pre Stack Time Migration) that has been corrected before, from the limit of inline 1198 to 1300 and crossline 10001 to 10736 with the sampling rate of $2 \mathrm{~ms}$ and interval time of -200 up to $2000 \mathrm{~ms}$.

For data processing, it used Hampson Russell software that consists of GEOVIEW to keep a well data base, ELOG for cross plotting between log properties, STRATA for inversion processing, wavelet extraction, the horizon picking as well as seismic-well tie and AVO for AVO analysis [8,9]. This research is conducted in several stages such as data collection, processing and data conditioning to obtain a result that would be analyzed.

This research is conducted in several stages such as data collection, processing and data conditioning to obtain a result that would be analyzed [10], as depicted in the flowchart:

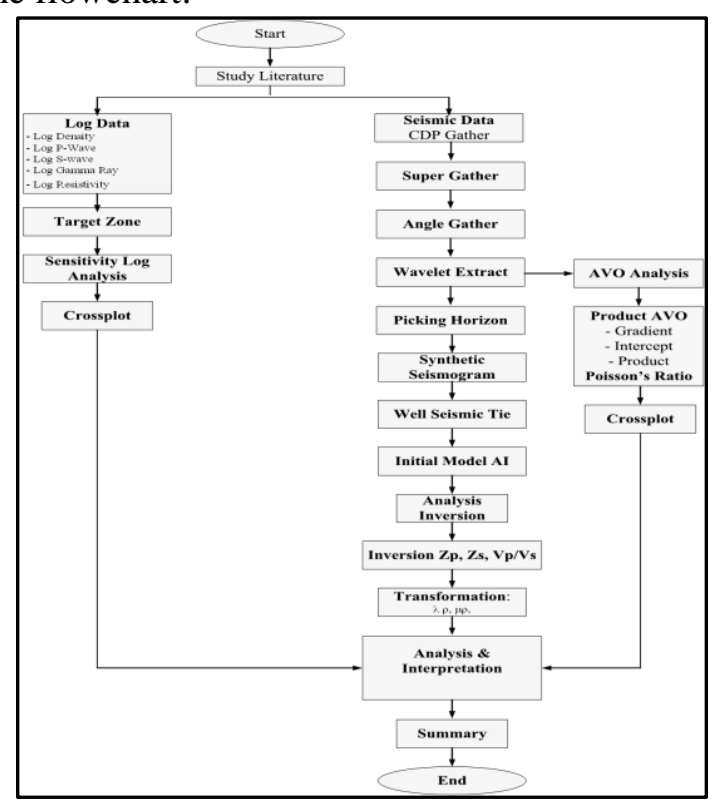

Figure 1.Research Flowchart

\section{RESULTS AND DISCUSSIONS}

\section{A. Well Log Data Analysis}

From well data analysis is conducted to identify and determine the target zone where it will be interpreted. This research used EP-036 well data in Gumai formation, EP field South Sumatra Basin, with the target zone at 714 to $722 \mathrm{~m}$ (TVD) or time domain 768 till $780 \mathrm{~ms}$.

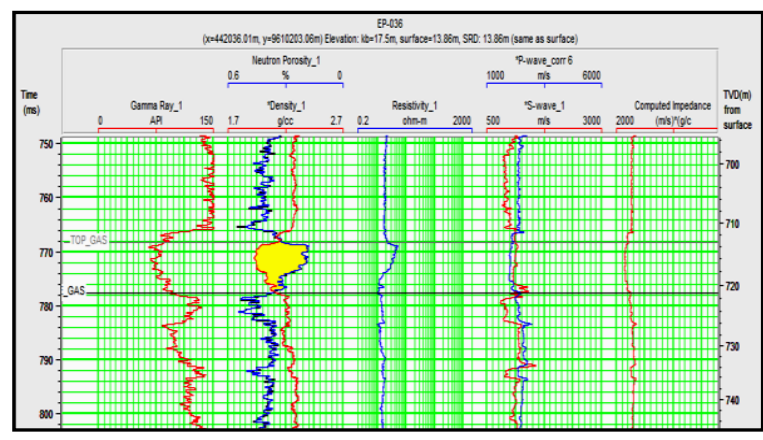

Figure 2.Well log data EP-036

Based on figure.2, it shows the cross line of porosity, neutron and density which have low value. It indicates the rock lithology is sandstone. Rocks contain of gases tended to have a lower hydrogen concentration than oil. Gamma ray shows the deflection to left that indicates the sandstone or carbonate with low shales. Resistivity deflected to the right that indicates a permeable zone consists of fluid which smaller than water resistivity, with effective porosity between 24 to $35 \%$ and water saturation 45 to $80 \%$ and low Vp/Vs.

\section{B. Data Sensitivity Analysis}

In order to control the area anomaly, this research used analysis of sensitivity data as cross plot $\log$. The more sensitive $\log$ the clearer of cut off zones. The cross plot log consists of gamma rays, porosity, water saturation, P-impedance, $\mathrm{Vp} / \mathrm{Vs}$ and $\lambda \mu \rho$.

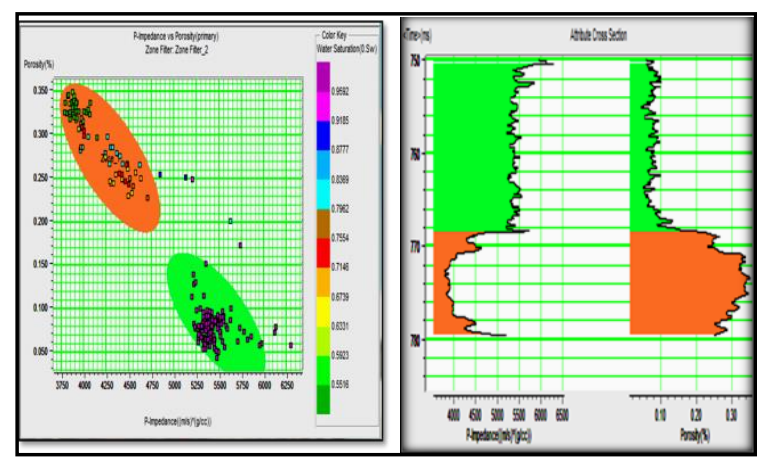

Figure 3 Cross Plot P impedance vs porosity

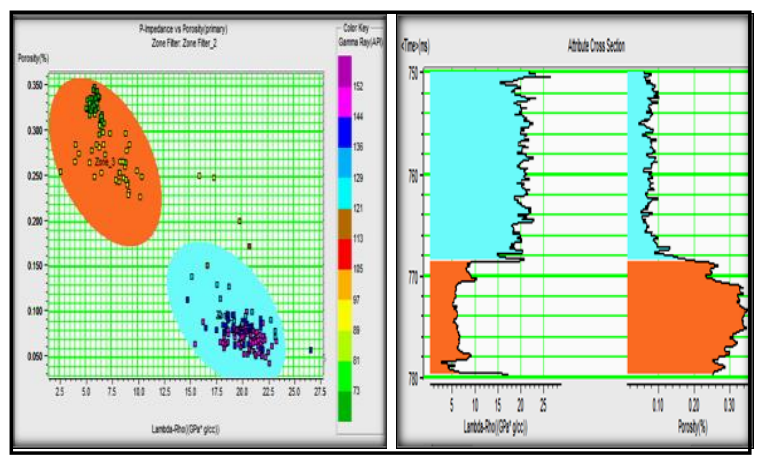

Figure 4 Cross Plot $\lambda \rho$ vs Porosity 

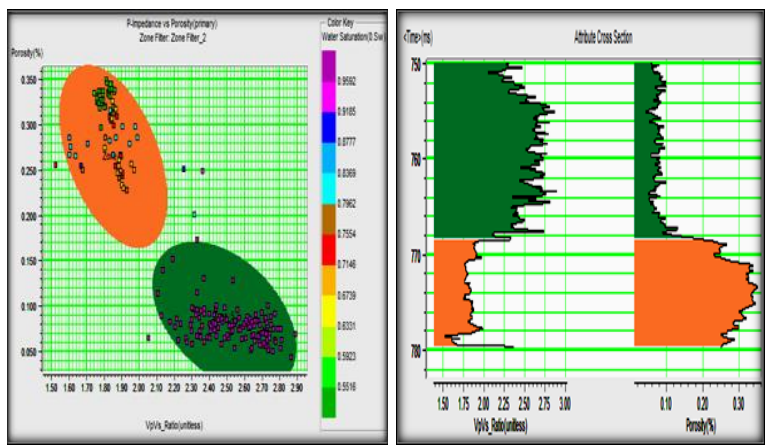

Figure 5 Cross Plot Vp/Vs vs Porosity
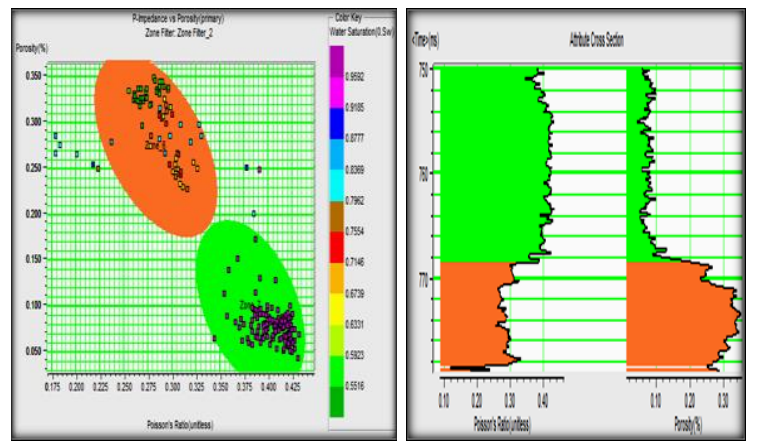

Figure 6 Cross Plot of Poisson's ratio vs Porosity

From cross plot analysis of sensitivity, almost all parameters give the separation effect of lithology and fluid, it could be said that EP-036 well is appropriate to do inversion process. Lithology at intervals the target zone consists of sandstone and shale. With a good porosity sandstone and bad porosity shale. The parameters that used to separate the lithology are gamma rays, acoustic impedance (P-impedance) and porosity. The fluid at intervals on target zone is the hydrocarbon gases filled in sandstone. The parameters used in to separate gas effect are water saturation, $\mathrm{Vp} / \mathrm{Vs}$, Poisson ratio, lambda-rho. It can be said that the target zone is the sandstone reservoir containing of hydrocarbon gases.

\section{Well seismic tie}

From well seismic tie is used to obtain correlations between EP 036 well and seismic data. In binding the well and seismic, it's used a check shoot data to convert the well data from depth domain into time domains. Then wavelet extraction is done, the next step is to create synthetic seismogram which is the result of convolutions between reflectivity coefficient and wavelet. Using the wavelet, the correlation coefficient between the real and synthetic seismic is calculated. The performed correlation value was 0.746 .

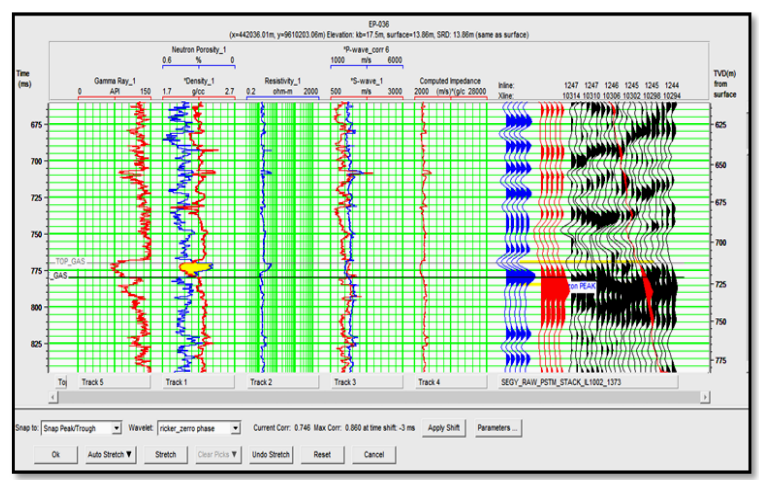

Figure 7 Well to seismic tie EP-036 well

\section{AVO Analysis.}

AVO analysis is performed on the pre-stack seismic data has been done the pre-conditioning. From the AVO response is the correlation between the changes of reflected signal amplitude to the dating angle [11]. It is obtained by AVO class in the EP-036 well inline 1247 belonged to the AVO class III, the low impedance contrast sands reservoir $[12,13]$. In this class, the reflection coefficient of normal incidence is always negative and more negative as the offset increased, besides the acoustic impedance is lower than the cap rock.

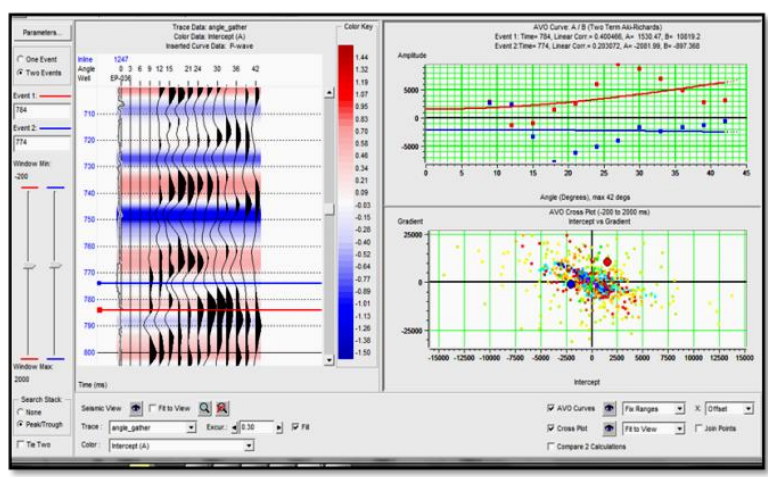

Figure 8. Curve 1247 AVO response from inline red:top marker and blue (base marker).

\section{E. Initial Model}

An initial model is required in the inversion process. This initial model is generated from log data (P-wave, S-wave and density) and seismic data with frequencies from 10 to $15 \mathrm{~Hz}$. In this case, the geological model is applied in area between the two horizons, i.e. interpolated horizon as the top layer and the GUF interpolated horizon as the bottom layer. From the Figure 8 it can be seen that the depth limited by two horizons ranged between 768 to $780 \mathrm{~m}$. 


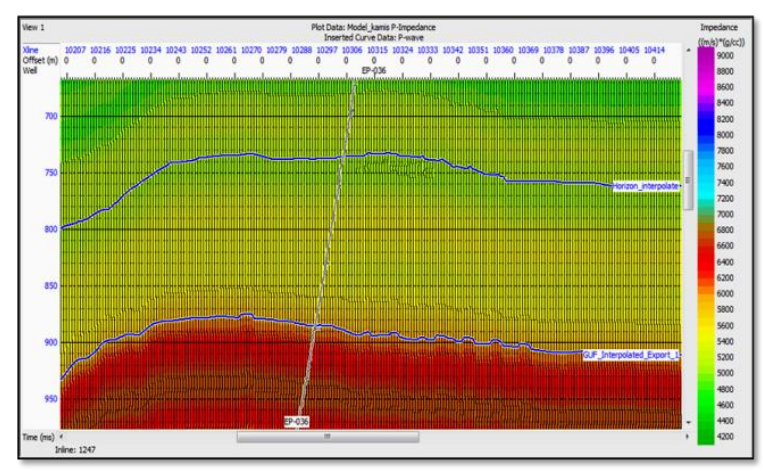

Figure 9 Initial Model

\section{F. Acoustic Impedance Inversion}

The result of acoustic impedance inversion analysis shows that the zones around Top Gas and Base Gas have a low value compared to the top and bottom with AI values: 4000-4800 (m/s) * (g/cc). (figure 10). Qualitatively sand and shale are well determinated based on contrast impedance values [12]. It means that a significant decrease in acoustic impedance indicates a good porosity lithology.

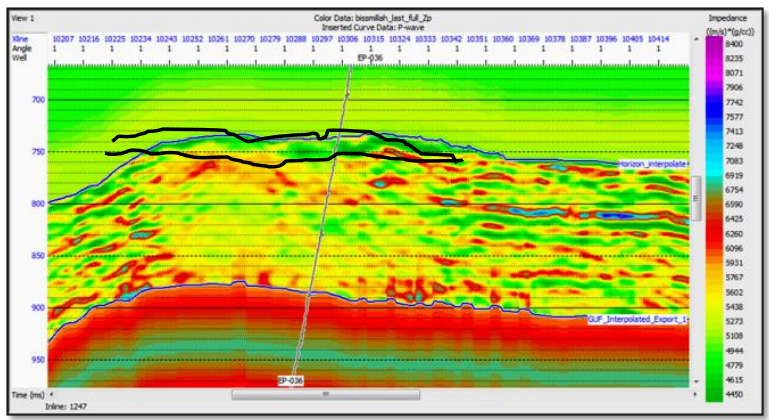

Figure 10 Results of Inversion Acoustic Impedance

\section{G. $\lambda \rho$ Inversion}

$\lambda \rho$ is generally sensitive to pore fluid, where it expresses resistance to volume changes when compression changes occur over a material or rock. The easier the material or rock is compressed, the smaller its lambda-rho value, otherwise the harder the stone to be compressed the greater value of its Lambda-Rho. Figure 10 shows the result of a $\lambda \rho$ transform from a cross section of simultaneous inversion. Zones around Top Gas and Gas Base have very low contrast of $\lambda \rho$ value compared to top and bottom which ranges from 10 to 16 . Sand and shale gas qualitatively are well determinated based on the contrast of $\lambda \rho$ values. It means that a significant decrease in Lambda-Rho indicated the indication of gas sand.

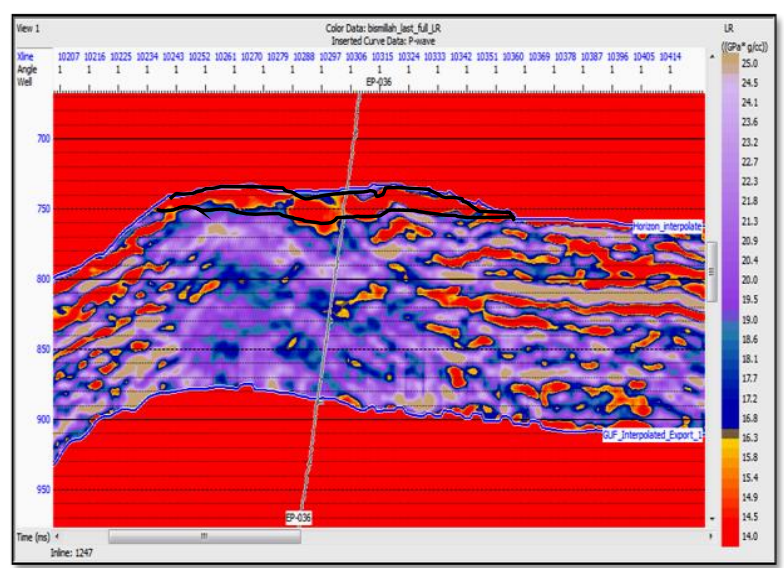

Figure 11 Results of Inversion $\lambda \rho$

\section{H. Vp/Vs Inversion}

The result of $\mathrm{Vp} / \mathrm{Vs}$ inversion analysis shows that the zones around Top Gas and Base Gas have a low value compared to the top and bottom with value 1,8 to 2,0 (figure 11 ). Qualitatively sand and shale gas can be well determined based on the contrast of $\mathrm{Vp} / \mathrm{Vs}$ values. It means that a significant decrease in $\mathrm{Vp} / \mathrm{Vs}$ ratio indicates the presence of lithology containing hydrocarbons, or the target zone is an indication of gas sand.

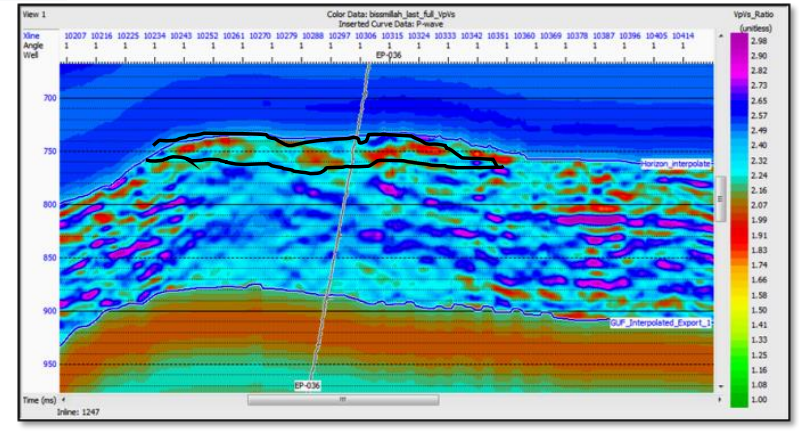

Figure 12 Results of Inversion $\mathrm{Vp} / \mathrm{Vs}$

Local anomaly of zone gas distribution is shown. Qualitatively, the poison ratio, acoustic impedance, $\mathrm{Vp} / \mathrm{Vs}$ ratio, and $\lambda \rho$ are controlled by seismic data slice map, there are similar patterns of seismic data that indicate the bright spot with other parameters. Quantitatively, each map showed a very low value, it is because of the contact of hydrocarbon gas. Therefore, it is recommended that the location of the drilling wells indicated by the symbol of the gas well in Figure. 8 with the reason that the overall parameters show similar responses and patterns.

\section{Slicing Map of Inversion}

Figure 10 shows the slicing map of inversion. Qualitatively, map of inversion acoustic impedance (AI), $\mathrm{Vp} / \mathrm{Vs}$, and $\lambda \rho$ have a similar pattern that indicate a bright spot. 


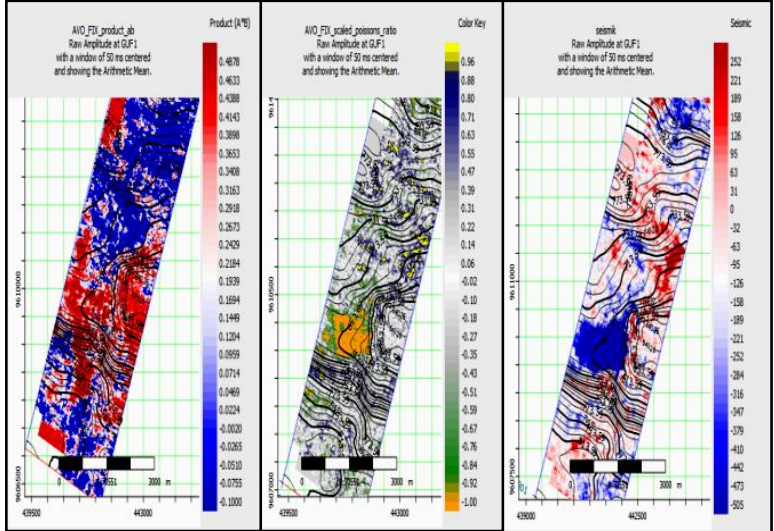

Figure 13 Slice map of AVO

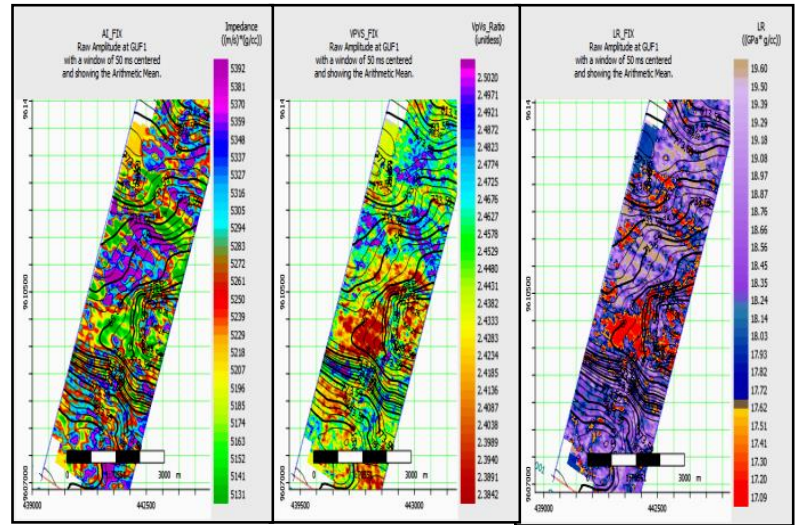

Figure 14. Slice Map of Inversion AI, Vp/Vs and $\lambda \rho$.

\section{CONCLUSIONS}

Based on data analysis and discussion to determine the reservoir characterization in the field $\mathrm{EP}$, it can be concluded that cross plot analysis of well log data EP036 shows that lithology is a reservoir containing gas hydrocarbons at depth of 768 to $780 \mathrm{~ms}$. The results of the sensitivity analysis of log data shows the parameter gamma ray, acoustic impedance, porosity, $\mathrm{Vp} / \mathrm{Vs}$ and $\lambda \rho$ can separate the lithology and fluid content qualitatively and quantitatively. Results of the intercept and gradient analyses based on Rutherford and William classifications, the EP field South Sumatra basin shows the presence of a class III gas sandstone, on the Gumai formation layer. Parameters $\lambda \rho$ and $\mathrm{Vp} / \mathrm{Vs}$ give a good result in differentiate lithology and fluid that shows in the cross plot analysis which is very sensitive to the changes of lithology and fluid. So this parameter can be used as the main parameter of physical properties analysis in relation to the reservoir characterization in EP field.

\section{ACKNOWLEDGMENT}

The author would like to thank PT. Pertamina EP Asset 2 for issuing permission to use the software, data and facilities to complete this research. The author also expresses his gratitude to Mr. M. Yusup Nur
Khakim, Ph.D., and Dr. Azhar Khaliq Affandi, M.Sc for their guidance and instruction to finish this research.

\section{REFERENCES}

[1] Goodway dan et.alll, "Improved AVO Fluid Detection and Lithology Discrimination Using Lame Petrophysical Parameters," Ann. Internat. Mtg. SEG, 1997.

[2] Irfan, Mashudi dan etc, "Seismic Inversion Analysis for Mapping the Porosity of the Sandstone Reservoir in the NF Field in the Central Sumatra Basin,” 2008.

[3] Castagna, P. John, Swan dan W. Herbert, "Principles of AVO crossplotting," 1997.

[4] Priyono dan Awali, "Seismic Method in Detection of Oil and Gas Reservoir (Application of AVO Method)," Jurnal JMS, vol. 5, pp. 9-22, 2000.

[5] K. Aki dan P. G. Richards, Quantitative Seismology, W.H.Freeman and Company, 2002.

[6] Wibisono dan Erlangga, "Simultaneous AVO Analysis and Inversion to Extract the Physical Properties of Rocks: A Case Study of the Gumai Formation in the Jambi Sub-Basin. Departement of Physic. Universitas of Indonesia.," Jambi, 2009.

[7] Bren dan Fitriyanie, "Lithology and Porosity Identification Using Inversion Analysis and Multi Seismic Attributes, Case Study of Blackfoot Field," Universitas Indonesia, Jakarta, 2011.

[8] O. Yilmaz, "Seismic Data Processing volume I \& II," Society of Exploration Geophysicists, Tulsa, 2001.

[9] B. a. H. D. Russell, “AVO Theory,” Hampson-Russel Software Service Ltd, 2011.

[10] D. P. B. H. R. Hampson, "Simultaneous Inversion of Pre-Stack Seismic Data," 2006.

[11] S. R. R. R. H. Williams, "Amplitude versus Offset variations in gas sands," Geophysics, vol. 54, pp. 680$688,1989$.

[12] Fatti dan et.all, "Detection of Gas in Sandstone Reservoirs Using AVO Analysis," 1994. 